\title{
Pharmacokinetic/Pharmacodynamic Modeling of the Antinociceptive Effects of (+)-Tramadol in the Rat: Role of Cytochrome P450 2D Activity
}

\author{
MARÍA J. GARRIDO, ONINTZA SAYAR, CRISTINA SEGURA, JAVIER RAPADO, MARÍA CARMEN DIOS-VIÉITEZ, \\ MARÍA JESÚS RENEDO, and IÑAKI F. TROCÓNIZ
}

Department of Pharmacy and Pharmaceutical Technology, School of Pharmacy, University of Navarra, Pamplona, Spain

Received December 05, 2002; accepted January 31, 2003

\begin{abstract}
In this study the role of cytochrome P450 2D (CYP2D) in the pharmacokinetic/pharmacodynamic relationship of (+)-tramadol $[(+)-T]$ has been explored in rats. Male Wistar rats were infused with (+)-T in the absence of and during pretreatment with a reversible CYP2D inhibitor quinine $(\mathrm{Q})$, determining plasma concentrations of $\mathrm{Q},(+)-\mathrm{T}$, and (+)-O-demethyltramadol [(+)-M1], and measuring antinociception. Pharmacokinetics of (+)-M1, but not (+)-T, was affected by Q pretreatment: early after the start of $(+)-T$ infusion, levels of $(+)$-M1 were significantly lower $(P<0.05)$. However, at later times during $Q$ infusion those levels increased continuously, exceeding the values found in animals that did not receive the inhibitor. These results suggest that CYP2D is involved in the formation and elimination of (+)-M1. In fact, results from another experiment
\end{abstract}

where $(+)-M 1$ was given in the presence and in absence of $Q$ showed that $(+)-\mathrm{M} 1$ elimination clearance $\left(\mathrm{CL}_{\mathrm{MEO}}\right)$ was significantly lower $(P<0.05)$ in animals receiving Q. Inhibition of both (+)-M1 formation clearance $\left(\mathrm{CL}_{\mathrm{M} 10}\right)$ and $\mathrm{CL}_{\mathrm{MEO}}$ were modeled by an inhibitory $E_{\mathrm{MAX}}$ model, and the estimates (relative standard error) of the maximum degree of inhibition $\left(E_{\mathrm{MAX}}\right)$ and $I C_{50}$, plasma concentration of $Q$ eliciting half of $E_{\mathrm{MAX}}$ for $\mathrm{CL}_{\mathrm{M} 10}$ and $\mathrm{CL}_{\mathrm{MEO}}$, were $0.94(0.04), 97(0.51) \mathrm{ng} / \mathrm{ml}$, and $48(0.42) \mathrm{ng} / \mathrm{ml}$, respectively. The modeling of the time course of antinociception showed that the contribution of (+)-T was negligible and (+)-M1 was responsible for the observed effects, which depend linearly on (+)-M1 effect site concentrations. Therefore, the CYP2D activity is a major determinant of the antinociception elicited after $(+)-T$ administration.
Tramadol (T) is a safe and effective analgesic used during the last two decades in the treatment of several types of pain (Rhoda et al., 1993; Raffa et al., 1995). Despite its long-term use, the understanding and prediction of the time course of its pharmacological effects are still hampered by the presence of active metabolites and the coexistence of opioid and nonopioid mechanisms. In fact, $\mathrm{T}$ is administered as a racemic mixture of two enantiomers, (+)-T and (-)-T, which are metabolized in the liver forming, among others, the two main active metabolites $(+)-O$-demethyltramadol $[(+)-\mathrm{M} 1]$ and (-)-O-demethyltramadol [(-)-M1], respectively. Data from literature suggest that $(+)$-enantiomers show opioid properties, while (-)-enantiomers are able to inhibit the uptake of

This work was supported by Grünenthal GmbH (Aachen, Germany).

Article, publication date, and citation information can be found at http://jpet.aspetjournals.org.

DOI: $10.1124 /$ jpet.102.047779. norepinephrine. This duality of action makes $\mathrm{T}$ an atypical opioid (Raffa et al., 1992; Raffa and Friderichs, 1996).

Recently the antinociceptive properties of the two active metabolites of T, (+)-M1 and (-)-M1, have been evaluated in the pharmacokinetic/pharmacodynamic ( $\mathrm{pk} / \mathrm{pd}$ ) perspective in the rat. The results showed that (+)-M1, in accord with its $\mu$-opioid receptor agonist properties (Lai et al., 1996), was able to produce maximum antinociception in the tail-flick test; however, when (-)-M1, a monoamine re-uptake inhibitor (Frink et al., 1996), was given alone, no significant effects were found (Valle et al., 2000). However, Garrido et al., 2000 showed that in the presence of (+)-M1, (-)-M1 significantly contributed to the antinociception elicited by the opioid, and this contribution could be well described by a mechanismbased $\mathrm{pk} / \mathrm{pd}$ model incorporating the known pharmacological properties of the two metabolite enantiomers.

The relative role of the enantiomers of $\mathrm{T}$ and $\mathrm{M} 1 \mathrm{in}$ anal-

\footnotetext{
ABBREVIATIONS: (+)-, (-)-M1, (+)-, (-)-O-demethyltramadol; (+)-, (-)-T, (+)-, (-)-tramadol; $C_{\mathrm{e}}$, concentration in the effect site; $\mathrm{CL}_{\mathrm{D}}$, distribution clearance; $\mathrm{CL}_{\mathrm{M} 10}$, initial (+)-M1 formation clearance; $\mathrm{CL}_{\mathrm{M} 2}$, clearance representing other routes of (+)-T elimination; $\mathrm{CL}_{\mathrm{MEO}}$, initial apparent (+)-M1 elimination clearance; CYP2D, D1, D6, cytochromes P450 2D, 2D1, and 2D6; $E_{0}$, baseline latency; HPLC, high-performance liquid chromatography; $k_{\mathrm{e} 0}$, first-order rate constant governing drug distribution from plasma to the effect site; pk/pd, pharmacokinetic/pharmacodynamic; $\mathrm{Q}$, quinine; RSE, relative standard error; $V$, apparent volume of distribution of the central compartment; $V_{\mathrm{T}}$, apparent volume of distribution outside the central compartment; $Z$, shape of the Weibull probability distribution.
} 
gesia after $\mathrm{T}$ administration is an issue that still has to be addressed properly for at least two main reasons: first, data from the literature suggest that $(+)-M 1$ is the main agent responsible for $\mathrm{T}$ effects (Poulsen et al., 1996), and second, the enzyme CYP2D6 is involved in M1 formation (Paar et al., 1992, 1997). Taking into account the fact that this enzyme is polymorphically expressed (Bertilsson et al., 1992) and eventually can be inhibited (Abdel-Rahman et al., 1999; Brynne et al., 1999), situations where the CYP2D6 activity is decreased are likely to occur, and therefore the relationship between the degree of enzyme activity and analgesic response needs to be established. In addition, to our knowledge the impact of alterations in CYP2D6 activity on M1 elimination has not been reported.

On the basis of these considerations, to gain a deeper understanding of the kinetics of the in vivo T effects, the goal of the present study was to investigate the impact of altered CYP2D activity on the pharmacokinetics (pk) of (+)-T and (+)-M1, and on the time course of response, quantifying the contribution of the parent drug and metabolite to the antinociceptive effects. To achieve these goals, (+)-T and (+)-M1 were given to rats in the absence and presence of quinine $(\mathrm{Q})$, a potent reversible inhibitor of the CYP2D cluster in the rat (Kobayashi et al., 1989).

\section{Materials and Methods}

\section{Chemicals}

(+)-T and (+)-M1 were obtained from Grünenthal GmbH (Aachen, Germany). Q, quinidine, and ketamine $\mathrm{HCl}$ were purchased from Sigma-Aldrich (Madrid, Spain). Anesthetics, xylazine (Xilagesic, 2\%) and ketamine (Ketolar, $50 \mathrm{mg}$ ) were purchase from Calier SA (Barcelona, Spain), and Parke-Davis (Barcelona, Spain), respectively. All the reagents and solvents were of analytical grade.

\section{Animals}

Male Wistar rats weighing 220 to $260 \mathrm{~g}$ were kept under laboratory standard conditions on a 12-h light/dark cycle with light from 8:00 $\mathrm{AM}$ to 8:00 $\mathrm{PM}$ in a temperature $\left(22^{\circ} \mathrm{C}\right)$-controlled room, and were acclimatized for a minimum of 2 days before experiments were performed. They were housed in individual cages after the surgical procedures, with free access to water. Food (standard laboratory rat, mouse, and hamster diets; Panlab SL, Barcelona, Spain) was withheld for $12 \mathrm{~h}$ before the start of experiments. The protocol of the studies was approved by the Animal Experimentation Committee of the University of Navarra.

\section{Surgical Procedure and Drug Administration}

Twenty-four hours before the start of the experiments three permanent cannulas were implanted under ketamine/xylazine (75:25 $\mathrm{mg} / \mathrm{kg}$ i.p.) anesthesia. One in the left femoral artery (0.3 mm i.d., 20 cm long; Vygon, Ecouen, France) was used for blood sample collection, one in the internal right jugular vein for saline or $\mathrm{Q}$ infusion, and the last one in the external right jugular vein for (+)-T or (+)-M1 administration ( $0.5 \mathrm{~mm}$ i.d., $10 \mathrm{~cm}$ long; Vygon). All cannulas were filled with a heparinized physiological saline solution $(20 \mathrm{IU} / \mathrm{ml})$ to prevent clotting and were tunneled under the skin and externalized on the dorsal surface of the neck.

Fresh stock solutions containing (+)-T, (+)-M1, or Q in concentrations of $21,3.75$, and $7 \mathrm{mg} / \mathrm{ml}$, respectively, were prepared just before the start of each experiment. (+)-T and (+)-M1 were dissolved in physiological saline, and $\mathrm{Q}$ in dimethylsulfoxide and further diluted with physiological saline 20:80 (v/v). Drug solutions were administered using a dual syringe pump (model 33; Harvard apparatus;
Panlab SL). The total volume administered did not exceed $1.5 \mathrm{ml}$ regardless of the duration of the infusions.

\section{Study Design}

The study is divided into two experiments. In experiments I and II (+)-T or (+)-M1 were the antinociceptive drugs given, respectively.

Experiment I. Twenty-four male Wistar rats were randomly allocated to four $(n=6)$ different groups. Group I, used as a control, received saline as an i.v. infusion for $80 \mathrm{~min}$. In the rest of the groups, animals received a 10-min i.v. infusion of 25 to $32 \mathrm{mg} / \mathrm{kg}$ to (+)-T. Ten minutes before (+)-T administration, saline was infused for $40 \mathrm{~min}$ in group II, and in groups III and IV, Q was given according to the following infusion scheme: $4 \mathrm{mg} / \mathrm{kg}$ were injected as an i.v. bolus followed by a $40 \mathrm{mg} / \mathrm{kg}$ dose infused in 40 (group III) or 80 (group IV) min.

Experiment II. Twelve male Wistar rats were divided at random into two $(n=6)$ groups. All animals received $3 \mathrm{mg} / \mathrm{kg}$ of $(+)-\mathrm{M} 1$ infused over $15 \mathrm{~min}$. Ten min before (+)-M1 administration, saline (group V) or Q (group VI) were infused for $40 \mathrm{~min}$. Group VI received $\mathrm{Q}$ as in group III. Figure 1 shows the experimental drug administration design used in the study.

In groups II-VI, to determine the pk of (+)-T, (+)-M1, and Q and to measure respiratory effects, several (7-10) blood samples (100$125 \mu \mathrm{l}$ ) were withdrawn at fixed intervals over the time course of the study. The volume of blood withdrawn did not exceed $10 \%$ of the total blood volume. Blood samples were immediately centrifuged at 2500 rpm for $15 \mathrm{~min}$ and the plasma was stored at $-20^{\circ} \mathrm{C}$ until HPLC analysis (see below).

In groups I-VI and in the pilot study receiving $\mathrm{Q}$ in a five-min i.v. infusion, antinociception was evaluated from the beginning of $\mathrm{Q}$ or saline administration to at least $3 \mathrm{~h}$ after the start of the experiments using the radiant-heat tail-flick technique (D'Amour and Smith, 1941). Antinociception was expressed as tail-flick latency (s) measured automatically with a Letica analgesimeter (Letica, Panlab SL). Baseline latencies were between 2.5 and $3.5 \mathrm{~s}$; animals with higher baseline latencies were excluded from the study. A maximum cutoff of $10 \mathrm{~s}$ was fixed to prevent tissue damage. Respiratory effects were evaluated quantifying the arterial levels of $\mathrm{pH}, \mathrm{pCO}_{2}$, and $\mathrm{pO}_{2}$ using a portable clinical analyzer (i-STAT portable clinical analyzer, Abbott, Barcelona, Spain).

\section{Drug Assays}

Q. Plasma concentrations of $\mathrm{Q}$ were determined by a sensitive HPLC assay. Forty $\mu \mathrm{l}$ of plasma were added to $110 \mu \mathrm{l}$ of an $\mathrm{NH}_{3}$ $(20 \%)$ solution containing the internal standard quinidine $\mathrm{HCl}(0.2$
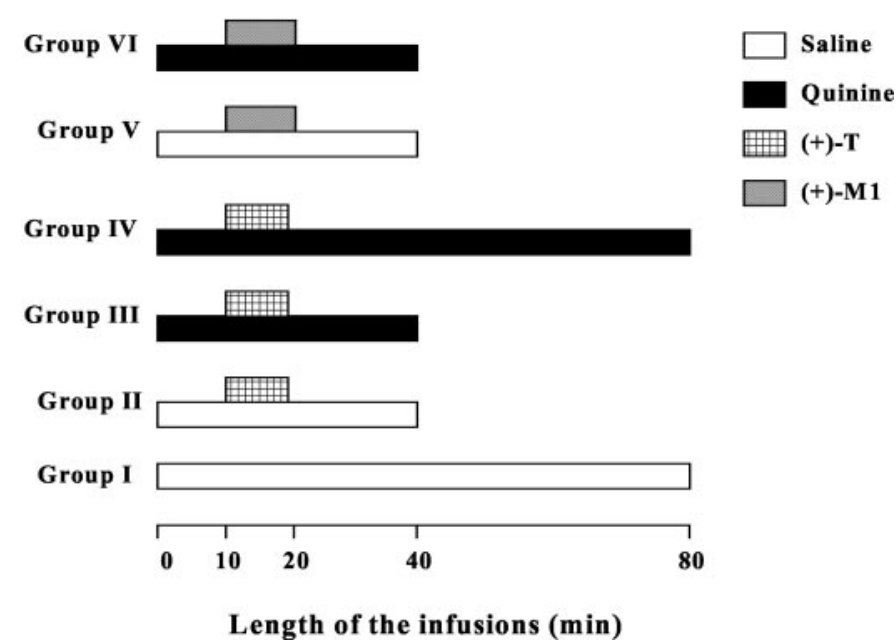

Fig. 1. Experimental design for saline, quinine, $(+)-\mathrm{T}$, and (+)-M1 administration in the different groups of animals used in the study. The length of the infusions is represented by the solid bars. 
$\mu \mathrm{g} / \mathrm{ml})$. This mixture was shaken and mixed with $1 \mathrm{ml}$ of a hexaneethyl acetate solution $(9: 1 ; \mathrm{v} / \mathrm{v})$. The organic layer was separated after shaking the mixture in vortex for $1 \mathrm{~min}$ and centrifuging at $4000 \mathrm{rpm}$ for $6 \mathrm{~min}$. This organic phase was evaporated to dryness at $35^{\circ} \mathrm{C}$ under reduced pressure (rotatory evaporator, model 43220000 ; Labconco, Kansas City, MO). The solid residue was reconstituted with $125 \mu \mathrm{l}$ of $0.9 \% \mathrm{NaCl}$ solution $(\mathrm{pH}=4.5)$ and a $100-\mu l$ aliquot was injected into the HPLC system.

The chromatographic system consisted of a Hewlett Packard HPLC HP 1100 equipped with a quaternary pump, autosampler, and fluorescence detector. The excitation and emission $\lambda$ were 346 and $442 \mathrm{~nm}$, respectively.

The analytical separation was performed at $35^{\circ} \mathrm{C}$ by an Ultrabase $\mathrm{C}_{18}$ column $(250 \times 4.6$-mm i.d. $)$ packed with cellulose Tris (3,5dimethylphenylcarbamate) coated in silica $(10 \mu \mathrm{m})$ (Scharlau, Barcelona, Spain), preceded by a $\mathrm{C}_{18}$ guard column (TR-C-160K1, Tracer, Barcelona, Spain). The mobile phase consisting of $\mathrm{H}_{2} \mathrm{O}$, acetonitrile, and a $10 \%$ acetic acid solution (10:14:76; v/v/v), was filtered through a $0.45-\mu \mathrm{m}$ pore size membrane filter. The flow rate was 1 $\mathrm{ml} / \mathrm{min}$.

Retention times of 10 and 12 min were found for quinidine and $\mathrm{Q}$, respectively. The accuracy of the assay was $<11 \%$. The intra and interassay coefficients of variation were less than $7 \%$. The method showed linearity within the concentration range studied and the limit of quantification was considered $4 \mathrm{ng} / \mathrm{ml}$.

(+)-T and (+)-M1. Plasma concentrations of (+)-T and (+)-M1 were determined by a sensitive and stereoselective HPLC assay (Campanero et al., 1999). Plasma samples (50 $\mu \mathrm{l})$ were transferred into glass tubes mixed with $50 \mu \mathrm{l}$ of internal standard (ketamine $\mathrm{HCl}$ ), $1 \mathrm{ml}$ of Tris buffer ( $\mathrm{pH} 9.5,0.05 \mathrm{M}$ ), and $6 \mathrm{ml}$ of tert-butyl methylether. The mixture was shaken for $1 \mathrm{~min}$ and the organic layer was separated after centrifugation at $3500 \mathrm{rpm}$ for $10 \mathrm{~min}$. The organic phase was evaporated to dryness at $40^{\circ} \mathrm{C}$ under reduced pressure (rotatory evaporator, model 43220000; Labconco). The residue was reconstituted in $250 \mu \mathrm{l}$ of mobile phase and mixed in vortex for $1 \mathrm{~min}$. A $100 \mu \mathrm{l}$ aliquot was then injected into the HPLC system.

The chromatographic system consisted of a Hewlett Packard HPLC HP 1100 equipped with a quaternary pump, autosampler, and fluorescence detector. The excitation and emission $\lambda$ were 199 and $301 \mathrm{~nm}$, respectively.

The analytical separation was performed at $20 \pm 3^{\circ} \mathrm{C}$ by a Chiralcel OD-R column $(250 \times 4.6-\mathrm{mm}$ i.d. $)$ packed with cellulose Tris (3,5-dimethylphenylcarbamate) coated in silica $(10 \mu \mathrm{m})$ (Daicel Chemical Industries, Tokyo, Japan), preceded by a reversed phase, $100 \times 4$-mm end-capped column packed with $3 \mu \mathrm{m}$ of $\mathrm{C}_{8}$ silica reversed phase particles (Hypersil BDS $\mathrm{C}_{18}$; Hewlett Packard). A guard column $(4 \times 4 \mathrm{~mm})$ packed with Lichrosphere 100 DIOL (5 $\mu \mathrm{m}$ ) from Merck (Barcelona, Spain) was connected to the column system. The mobile phase consisting of acetonitrile plus $0.05 \mathrm{M}$ sodium dihydrogen phosphate, thiethylamine $(0.09 \mathrm{M})$, and sodium perchlorate $(0.2 \mathrm{M})$, adjusted to $\mathrm{pH} 5.5$ with hydrochloric acid $2 \mathrm{M}(20$ acetonitrile/80 buffer, $\mathrm{pH} 5.5$ ), was filtered through a $0.45-\mu \mathrm{m}$ pore size membrane filter. The flow rate was $0.6 \mathrm{ml} / \mathrm{min}$.

Retention times of 40 and 15 min were found for (+)-T and (+)-M1, respectively. The accuracy of the assay was $<15 \%$. The intra and interassay coefficients of variation were less than $5 \%$. The method was linear within the concentration range studied and the limit of quantification was considered $10 \mathrm{ng} / \mathrm{ml}$ for both compounds.

Data Analysis. All analyses were performed with NONMEM, version V, level 1.1 (Beal and Sheiner, 1992) using the population approach that allows the estimation of the fixed (typical population) and random (interanimal and residual variability) parameters. Interanimal variability (IAV) was modeled exponentially and expressed as coefficient of variation. Differences between the observed drug plasma concentrations and model predictions were modeled with proportional error models. To describe the time course of antinociception a survival analysis was performed (see below) and therefore, a residual error model does not apply.
Model selection was based on a number of criteria, such as the exploratory analysis of the goodness-of-fit plots, the estimates, and the precision (represented by the relative standard error [RSE] computed as the ratio between the standard error and the parameter estimate) of the fixed and random parameters, and the minimum value of the objective function (OBJ) provided by NONMEM. The difference in the OBJ between two hierarchical models was compared with a $\chi^{2}$ distribution in which a difference of 6.63 points is significant at the $1 \%$ level.

Data from experiments I and II were fitted separately in three steps: step 1, pk analysis of Q in plasma; step 2, the model selected in step 1 and its parameter estimates were used to characterize the $\mathrm{Q}$ versus (+)-T and $\mathrm{Q}$ versus (+)-M1 interactions; step 3, using the models selected during steps 1 and 2 and its parameter estimates, the time course of antinociceptive response was modeled.

Pk Modeling. Step 1: kinetics of Q in plasma was described using standard compartmental models; step 2: Fig. 2 shows the model used to describe the plasma versus time profiles of (+)-T and (+)-M1 obtained from experiment $\mathrm{I}$ in the presence and in absence of $\mathrm{Q}$. Formation of (+)-M1 was described by a first-order process that was assumed to be reversibly inhibited by the presence of $\mathrm{Q}$ :

$$
\mathrm{CL}_{\mathrm{M} 1}=C L_{M 10} \times\left(1-E_{\mathrm{MAX}} \times \frac{C_{\mathrm{Q}}}{C_{\mathrm{Q}}+\mathrm{IC}_{50}}\right)
$$

Where $\mathrm{CL}_{\mathrm{M} 1}$ is the (+)-M1 formation plasma clearance at any time of the experiment, $\mathrm{CL}_{\mathrm{M} 10}$ is the (+)-M1 formation plasma clearance in absence of Q, $E_{\mathrm{MAX}}$ is the maximum Q-induced decrease in $\mathrm{CL}_{\mathrm{M} 10}$, and $\mathrm{IC}_{50}$ is the plasma concentration of $\mathrm{Q}\left(C_{\mathrm{Q}}\right)$ eliciting half of $E_{\mathrm{MAX}}$. The estimate of $E_{\mathrm{MAX}}$ was constrained between 0 and 1 . During the analysis the apparent volumes of distribution of the central compartment for (+)-T and (+)-M1 were assumed to be the same.

Results from experiment II (see below) showed that elimination of (+)-M1 was also impaired in the presence of $\mathrm{Q}$, thus the same inhibitory model was used to describe the decrease in the plasma (+)-M1 clearance $\left(\mathrm{CL}_{\mathrm{ME0}}\right)$. During the model-building process different estimates of $E_{\mathrm{MAX}}$ and $\mathrm{IC}_{50}$ for the case of $\mathrm{CL}_{\mathrm{M} 10}$ and $\mathrm{CL}_{\mathrm{MEO}}$ inhibition were tested. In addition, the presence of more than one route of elimination for (+)-T and (+)-M1 was also evaluated. A detailed description of the key models explored during this step is presented Appendix I.

Pd Modeling. From the total of effect measurements in both experiments, $30 \%$ were censored (i.e., recorded as $10 \mathrm{~s}$ ). To integrate appropriately the censored information in the analysis the time-toevent approach was used (Luks et al., 1998) where the time at which the animal responds to the nociceptive stimuli is given by a probability density distribution. In the present study, the Weibull distribution (Klein and Moeschberger, 1997; Luks et al., 1998), which is

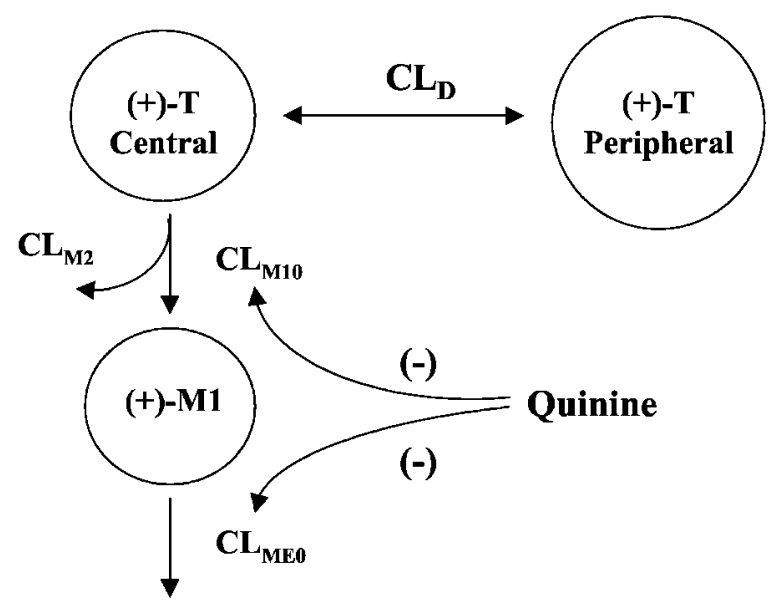

Fig. 2. Schematic representation of the model selected to describe the pharmacokinetic data from experiment I. 
TABLE 1

Pharmacokinetic parameters of $Q$ in rats

\begin{tabular}{lcc}
\hline \multicolumn{1}{c}{ Parameter } & Estimate $(\mathrm{RSE})$ & IAV $(\mathrm{RSE})$ \\
\hline$V(\mathrm{l})$ & $0.36(0.14)$ & $42(0.55)$ \\
$V_{\mathrm{T}}(\mathrm{l})$ & $0.88(0.18)$ & $30(0.53)$ \\
$\mathrm{CL}_{\mathrm{D}}(1 / \mathrm{min})$ & $0.051(0.19)$ & N.E. \\
$\mathrm{CL}(1 / \mathrm{min})$ & $0.024(0.21)$ & $72(0.58)$
\end{tabular}

$V$, apparent volume of distribution of the central compartment; $V_{\mathrm{T}}$, apparent volume of distribution of the peripheral compartment; $\mathrm{CL}_{\mathrm{D}}$, distribution clearance; $\mathrm{CL}$, elimination clearance; IAV, interanimal variability expressed as coefficient of variation; RSE, relative standard error; N.E., not estimated.

characterized by the median time to response $(M)$ and the shape of the probability distribution $(Z)$, was used. $M$ was expressed as follows: $E_{0}+f\left(C_{\mathrm{e}}\right)$, where $E_{0}$ represents the baseline latency, $f$ is the pharmacodynamic model (i.e., linear, $E_{\mathrm{MAX}}$, or sigmoidal $E_{\mathrm{MAX}}$ ), and $C_{\mathrm{e}}$ corresponds to effect site concentrations (Sheiner et al., 1979) of (+)-T or (+)-M1. An eventual interaction between the parent drug and its metabolite was also evaluated; in this case the general model $E_{0}+f\left(C_{\mathrm{e}}(+)-\mathrm{M} 1, C_{\mathrm{e}}(+)-\mathrm{T}\right)$ was applied, $f$ being an interaction (i.e., additive, non, or competitive) model. The value of $Z$ was assumed to be independent of drug concentration. Appendix II describes the key models fitted during this step of the analysis.

The likelihood of each noncensored time to response (i.e., $<10 \mathrm{~s}$ ) is proportional to the density evaluated at that observed time to response; in the case of a censored observation (i.e., $=10 \mathrm{~s}$ ), the likelihood is proportional to the area under the Weibull density curve from $10 \mathrm{~s}$ to $\infty$ (survival). The expressions corresponding to density $(D)$ and survival $(S)$ are:

$$
\begin{gathered}
D=Z \times\left(\frac{\text { Observation }}{M}\right)^{Z} \times \ln (2) \times \frac{S}{\text { Observation }} \\
S=0.5\left(\frac{\text { Observation }}{M}\right)^{Z}
\end{gathered}
$$

Where observation refers to observed response latency.

Statistical Analysis. To evaluate differences within each group in respiratory parameters with respect to baseline, a paired Student's $t$ test was used. Differences between groups in latencies and respiratory parameters at baseline were evaluated with an analysis of variance test followed by the $\mathrm{F}$ test. A probability level of $P<0.05$ was considered to be statistically significant. Raw data are expressed in the text as mean (standard deviation [S.D.]) and model-derived parameters as their estimate (RSE).

\section{Results}

Animals in the control and in the Q pilot study groups did not show significant antinociception or changes in the respi-

TABLE 2

Quinine CYP2D inhibition and (+)-T and (+)-M1 pharmacokinetic parameters in the rat

\begin{tabular}{lcc}
\hline \multicolumn{1}{c}{ Parameter } & Estimate $(\mathrm{RSE})$ & IAV $(\mathrm{RSE})$ \\
\hline$V(\mathrm{l})$ & $0.055(0.8)$ & N.E. \\
$V_{\mathrm{T}}(\mathrm{l})$ & $0.88(0.04)$ & $14(0.41)$ \\
$\mathrm{CL}_{\mathrm{D}}(1 / \mathrm{min})$ & $0.16(0.15)$ & N.E. \\
$\mathrm{CL}_{\mathrm{M} 10}(1 / \mathrm{min})$ & $0.0019(0.43)$ & N.E. \\
$\mathrm{CL}_{\mathrm{M} 2}(1 / \mathrm{min})$ & $0.0061(0.12)$ & $30(0.19)$ \\
$\mathrm{CL}_{\mathrm{ME0}}(1 / \mathrm{min})$ & $0.018(0.42)$ & N.E. \\
$E_{\mathrm{MAX}}$ & $0.94(0.04)$ & N.E. \\
$\mathrm{IC}_{50 \_C L M 10}(\mathrm{ng} / \mathrm{ml})$ & $97.2(0.51)$ & N.E. \\
$\mathrm{IC}_{50 \_C L M E 0}(\mathrm{ng} / \mathrm{ml})$ & $47.8(0.42)$ & N.E. \\
\hline
\end{tabular}

$V$, apparent volume of distribution of the central compartment; $V_{\mathrm{T}}$, apparent volume of distribution of the peripheral compartment; $\mathrm{CL}_{\mathrm{D}}$, distribution clearance; $\mathrm{CL}_{\mathrm{M} 10}$ initial (+)-M1 formation clearance; $\mathrm{CL}_{\mathrm{M} 2}$, plasma clearance representing other routes of (+)-T elimination; $\mathrm{CL}_{\mathrm{ME} 0}$, initial apparent (+)-M1 elimination clearance; $E_{\mathrm{MAX}}$, maximum degree of inhibition in $\mathrm{CL}_{\mathrm{M} 10}$ and $\mathrm{CL}_{\mathrm{ME} 0}$ that quinine is able to induce; $\mathrm{IC}_{50 \_C L M 10}$, and $\mathrm{IC}_{50 \_C L M E 0}$, plasma concentrations of quinine eliciting half of $E_{\mathrm{MAX}}$ on $\mathrm{CL}_{\mathrm{M} 10}$ and $\mathrm{CL}_{\mathrm{ME} 0}$, respectively; IAV, interanimal variability expressed as coefficient of variation; RSE, relative standard error; N.E., not estimated. ratory parameters during and after the saline or $\mathrm{Q}$ infusion, respectively $(P>0.05)$. Baseline latency and respiratory parameter values did not differ significantly $(P>0.05)$ among all groups of animals. Mean (S.D.) baseline latency and respiratory parameter values were $2.8(0.1) \mathrm{s}, 7.51(0.03$; $\mathrm{pH}), 80.2\left(6.3 ; \mathrm{pO}_{2}\right)$, and $35.1\left(5.2 ; \mathrm{pCO}_{2}\right)$, respectively.

\section{Experiment I}

Step I: pk Modeling of $\mathbf{Q}$. Figure 3 shows the mean $Q$ observed plasma concentrations versus time profiles in groups III and IV. Maximum $\mathrm{Q}$ concentrations in plasma were achieved at the end of the infusion and showed mean (S.D.) values of 7150 (1214), group III, and 5137 (1387) ng/ml, group IV. The kinetics of Q in plasma was best described with a two-compartment model with interanimal variability associated to plasma clearance (CL), and apparent volumes of distribution of the central $(V)$ and peripheral $\left(V_{\mathrm{T}}\right)$ compartments. Table 1 lists the estimates of the pk parameters, and typical population predictions are also shown in Fig. 3.

Step II: Simultaneous pk Modeling of (+)-T and (+)M1. The six panels in Fig. 4 show the mean observed plasma concentrations versus time profiles of $(+)-\mathrm{T}$ and $(+)-\mathrm{M} 1$. In group II (upper and lower left panels) (+)-M1 formation was very rapid; at the time the infusion of $(+)-\mathrm{T}$ was stopped the plasma (+)-M1 concentrations reach the maximum with a mean (S.D.) value of $772(188) \mathrm{ng} / \mathrm{ml}$. From the middle and right panels in Fig. 4 it is apparent that the kinetics of $(+)-\mathrm{T}$ in plasma remained almost unaffected by the presence of $Q$; on the contrary, the plasma versus time profiles of (+)-M1 showed major changes. It is clear that, at least, at early times after the start of (+)-T infusion formation of (+)-M1 is impaired. For example, mean (S.D.) observed (+)-M1 levels 5 min after the start of the infusion were 411 (222), 88 (23), and 24 (1.5) ng/ml for groups II-IV, respectively. The corresponding levels $10 \mathrm{~min}$ after the start of the infusion were 772 (188), 152 (51), and 113 (42) ng/ml for groups II-IV, respectively. However, and despite the presence of $Q$ in plasma (see Fig. 3), levels of (+)-M1 increased continuously, reaching a maximum at 120 (group III) and 60 (group IV) min, respectively. At these times and until end of the experiment, (+)-M1 levels in groups III and IV were similar to or even higher than in group II. On the basis of these observations, it can be anticipated that a model considering only an effect of

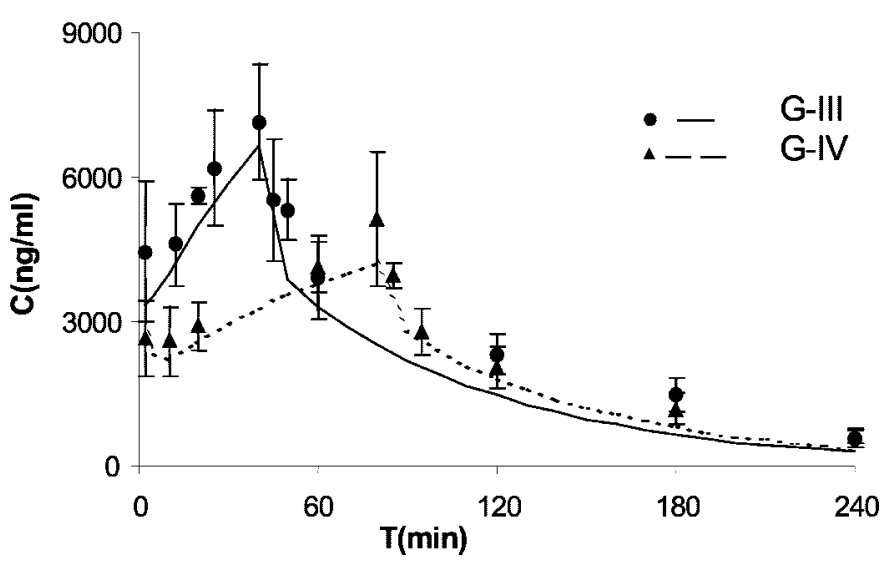

Fig. 3. Plasma $Q$ concentration versus time profiles. Symbols, mean raw data: circles (G-III), triangles (G-IV). Lines represent typical model predictions: solid (G-III), dashed (G-IV). Vertical lines correspond to standard deviation. 
TABLE 3

Pharmacokinetic/pharmacodynamic parameters of (+)-M1 in the rat

\begin{tabular}{llr}
\hline \multicolumn{1}{c}{ Parameter } & Estimate $(\mathrm{RSE})$ & IAV $(\mathrm{RSE})$ \\
\hline$E_{\mathrm{O}}(\mathrm{s})$ & $2.77(0.04)$ & $5(0.25)$ \\
Slope $(\mathrm{s} \cdot \mathrm{ml} / \mathrm{ng})$ & $0.0123(0.11)$ & $46(0.36)$ \\
$k_{\mathrm{eO}}(\mathrm{l} / \mathrm{min})$ & $0.0665(0.11)$ & N.E. \\
$Z$ & $6.64(0.075)$ & N.E.
\end{tabular}

$E_{0}$, baseline latency; slope, slope of the linear relationship between response and effect site concentrations; $k_{\mathrm{e} 0}$, first-order rate constant governing the distribution from plasma to the effect site; $Z$, parameter representing the shape of the Weibull distribution; IAV, interanimal variability expressed as coefficient of variation; RSE relative standard error; N.E., not estimated.

$\mathrm{Q}$ on $\mathrm{CL}_{\mathrm{M} 10}$ would not be enough to describe the data. The dashed lines in Fig. 4 represent the predictions from such a model [model 2 (Appendix I)] and clearly show the lack of fit, evidencing the need for an extra effect of $\mathrm{Q}$. Taking into account the fact that $\mathrm{Q}$ was able to reduce (+)-M1 elimination (see results from experiment II), a model including an additional inhibitory effect of $\mathrm{Q}$ on $\mathrm{CL}_{\mathrm{MEO}}$ was fitted to the data, resulting in a better fit (solid lines in Fig. 4 and model 7 (Appendix I)]. The difference in the OBJ value between the two cited models was 102 points for one additional parameter $(P<0.001)$. Other features of the selected model are 1$)$ the two compartments describing (+)-T disposition; 2 ) the presence of a second elimination pathway for (+)-T; 3) the monocompartmental disposition properties of (+)-M1; and 4) the difference in the inhibitory potency of $\mathrm{Q}$ with respect to $\mathrm{CL}_{\mathrm{M} 10}$ and $\mathrm{CL}_{\mathrm{ME} 0}$, reflected in the estimates of the $\mathrm{IC}_{50}$ listed in Table 2. These features were selected on the basis of the results from the model development process (see Appendix I). The rest of the pk parameters of (+)-T and (+)-M1 are also listed in Table 2.
Step III: pk/pd Modeling of the Antinociceptive Effects. Mean raw effect versus time data represented in Fig. 5 resembled the (+)-M1 concentration versus time profiles shown in Fig. 4, suggesting that (+)-M1 plays a major role in the observed antinociception. In fact, a difference in OBJ of -95 points was found between the models using (+)-T [model 3 (Appendix II)] or (+)-M1 [model 4 (Appendix II)] effect site concentrations as the active compound. Results from models describing the observed effects based on a pd interaction between (+)-T and (+)-M1 [model 5 (Appendix II)] indicated that the contribution of (+)-T to antinociception was negligible. The final selected model linearly relates $M$ with effect site concentrations of (+)-M1. More complex relationships such $E_{\text {MAX }}$ [model 6 (Appendix II)] or sigmoidal (not shown) did not significantly improve the fit $(P>0.05)$. IAV variability was estimated in baseline and in the slope parameter of the linear model. Table 3 lists the estimates of the pd parameters and Fig. 5 shows also the typical model predicted antinociception versus time profiles.

\section{Experiment II}

Step I: pk Modeling of $\mathbf{Q}$. In this experiment individual fitting was performed and then mean and standard deviation of the parameters were computed (Steimer et al., 1984). This procedure was carried out because the population analysis with six rats did not provide adequate results. Q plasma concentration versus time profiles obtained during this experiment were similar to those obtained for group III. Mean (S.D.) estimates of $V, V_{\mathrm{T}}$, distribution clearance $\left(\mathrm{CL}_{\mathrm{D}}\right)$, and $\mathrm{CL}$ were $0.25(0.11) \mathrm{l}, 0.93(0.18) \mathrm{l}, 0.078(0.06) \mathrm{l} / \mathrm{min}$, and $0.012(0.003)$ $1 /$ min, respectively; values close to the estimates found in experiment I (see Table 1).
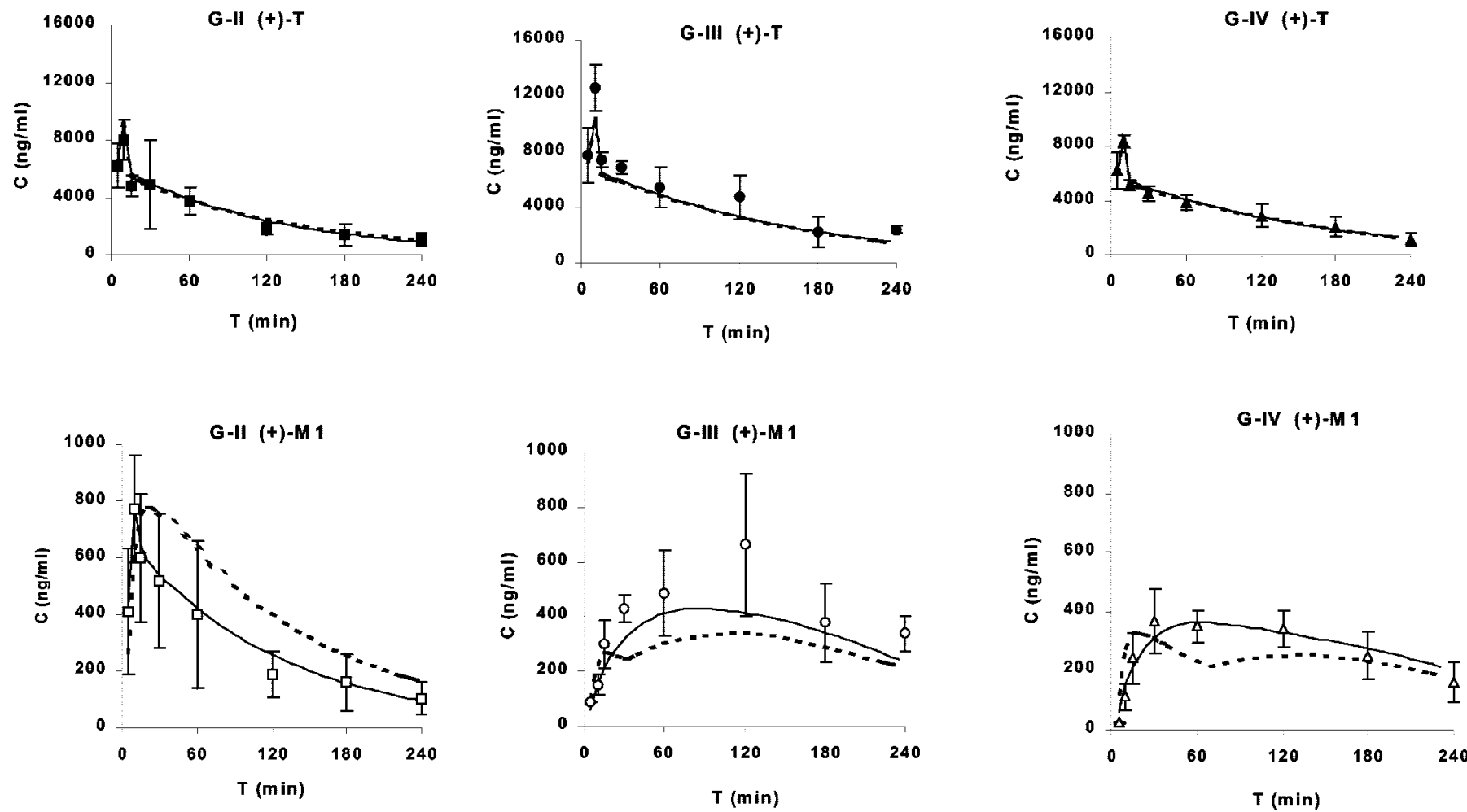

Fig. 4. Plasma (+)-T (upper panels) or (+)-M1 (lower panels) concentration versus time profiles. Group II, left panels (G-II), group III, middle panels (G-III), and group IV, right panels (G-IV). Symbols represent mean raw data and vertical lines correspond to standard deviations. Lines show typical predictions from the selected model (solid lines) and the model that did not include an inhibitory quinine effect on (+)-M1 elimination (dashed lines) 
Step II: pk Modeling of (+)-M1. Figure 6 (left panel) shows the mean observed plasma concentration versus time profiles in groups V and VI, where it is clear that the presence of Q impaired (+)-M1 elimination. Inhibitory effects of Q were modeled as in the analysis of experiment I data. Estimates (RSE) of $E_{\mathrm{MAX}}$ and $\mathrm{IC}_{50}$ were $0.95(0.18)$ and $83(0.53)$ $\mathrm{ng} / \mathrm{ml}$, respectively. When (+)-M1 was infused in rats a twocompartment model significantly improved the fit with respect to the simpler one-compartment model $(P<0.05)$. Estimates (RSE) of $V, V_{\mathrm{T}}, \mathrm{CL}_{\mathrm{D}}$, and CL were $0.32(0.17) \mathrm{l}$, $0.96(0.10) \mathrm{l}, 0.08(0.26) \mathrm{l} / \mathrm{min}$, and $0.022(0.13) \mathrm{l} / \mathrm{min}$, respectively. IAV (RSE) was estimated in $V$ and $C L$ with values of $41(0.47) \%$ and $80(0.81) \%$, respectively. Effects of Q were also evaluated in the rest of the pk parameters but no significance $(P>0.05)$ was found. Lines in Fig. 6 (left panel) represent the adequacy of the selected model.

Step III: pk/pd Modeling of the Antinociceptive Effects. The right panel in Fig. 6 shows that antinociceptive effects in group VI are maintained for a longer period of time with respect to group V. This observation was expected, taking into account the difference in the (+)-M1 plasma versus time profiles seen in the left panel of Fig. 6. The model used to describe the time course of response data was similar to the one fitted to the experiment I data. Estimates (RSE) of baseline, the slope of the linear effect versus effect site concentration relationship, $k_{\mathrm{e} o}$, the first-order rate constant governing drug distribution from plasma to the effect site, and $Z$ were $2.81(0.02) \mathrm{s}, 0.0214(0.02) \mathrm{s} \cdot \mathrm{ml} / \mathrm{ng}, 0.0485(0.14) \mathrm{l} / \mathrm{min}$, and $4.51(0.15)$, respectively. IAV (RSE) was estimated in baseline and slope with values of $6(0.16) \%$ and $24(0.33) \%$, respectively. Model estimates between both experiments were also similar (see Table 3). At later times after the start of the experiment in group VI the model provided typical predictions higher than the median observed values, which should not be interpreted totally as a lack of fit, since the use of the time-to-event approach allows response predictions to be higher than $10 \mathrm{~s}$ (cutoff time). To improve the overprediction of the observed data at 180 min different tolerance models were fitted to the data (Gårdmark et al., 1999), but no improvements were achieved.

\section{Discussion}

It has been suggested that in the analgesic response to $\mathrm{T}$ several mechanisms of action can be involved, in addition to the metabolite contribution (Raffa et al., 1995). Taking into account this complex scenario, the current research represents the third of a series of studies with the goal of understanding and predicting the in vivo time course of $\mathrm{T}$ effects, where the key parts of the system are treated separately. In previous reports the in vivo characterization of (+)-M1 and (-)-M1 was carried out (Garrido et al., 2000; Valle et al., 2000). Results showed that the pk/pd approach was suitable to describe their in vivo effects reflecting their pd properties studied previously in in vitro studies. However, to our knowledge the respective contributions of $\mathrm{T}$ and $\mathrm{M} 1$ enantiomers to the response has not been quantified. There are in vitro as well as clinical data suggesting that (+)-M1 plays an important role. For example, it shows a moderate affinity for $\mu$-opioid receptors (Lai et al., 1996), and individuals with an impaired (+)-M1 formation (poor metabolizers) showed a decreased degree of analgesia after $\mathrm{T}$ administration (Poulsen et al., 1996). Since (+)-M1 formation in humans is governed by the enzyme CYP2D6 (Paar et al., 1992, 1997), the identification of factors affecting the CYP2D6 activity
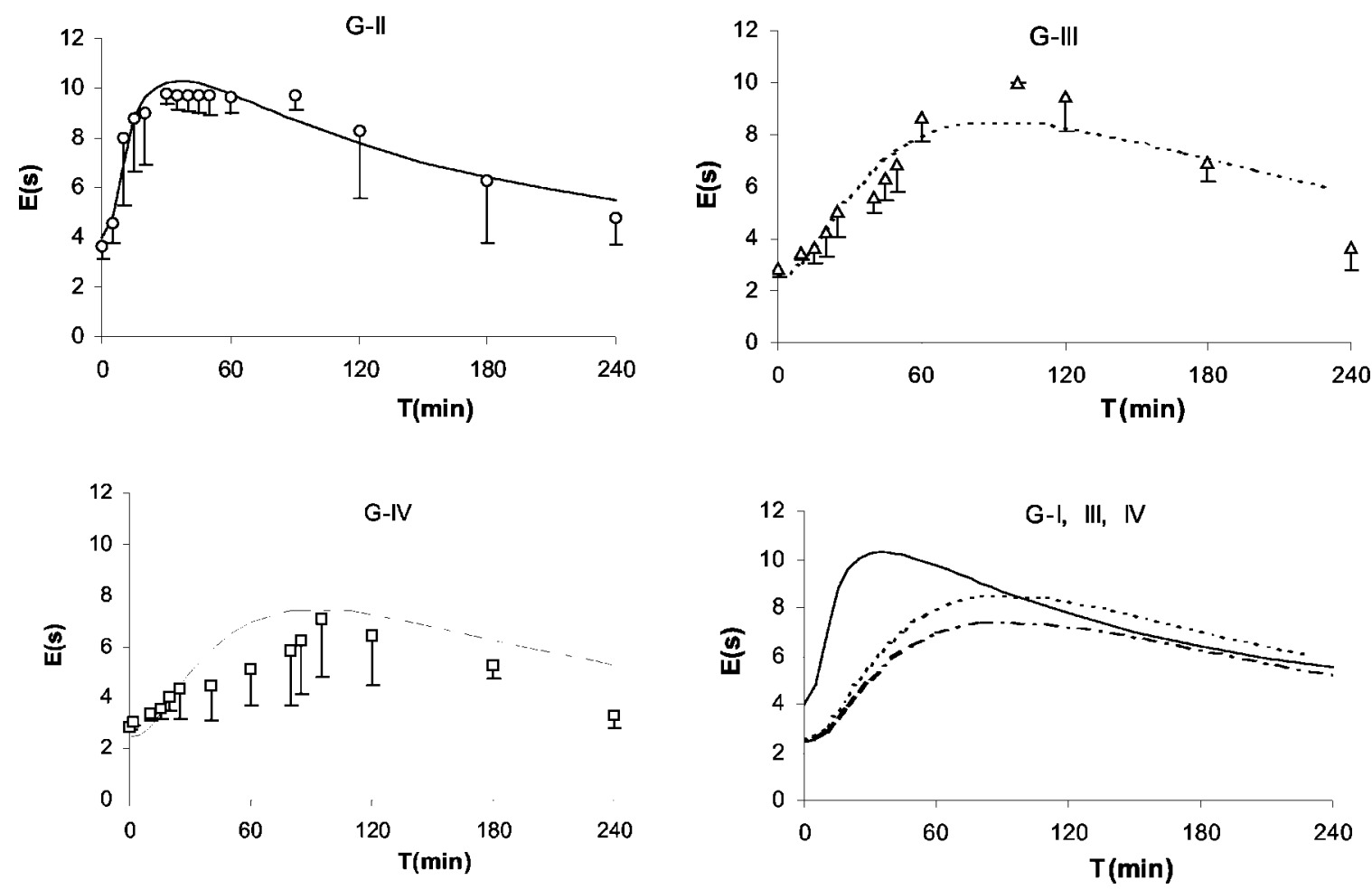

Fig. 5. Time course of antinociception. Symbols, median raw data. Vertical lines represent the dispersion in the data and have a value equal to the standard deviation of the mean. Lines show typical model predicted effect versus time profiles. 
and establishing the relationship between such activity and analgesia are required to optimize the use of $\mathrm{T}$.

In this study a pk/pd model was developed that allows us to explore the impact of alterations in CYP2D cluster activity in the time course of antinociception after (+)-T administration in rats. CYP2D1 activity in the rat has been used as a model of CYP2D6 activity in humans (Al-Dabbagh et al., 1981); however, there are data suggesting that in the rat, debrisoquine hydroxylation is not restricted to CYP2D1 (Kahn et al., 1985). For this reason the general notation of CYP2D has been used in the text.

Alteration of CYP2D activity was achieved infusing Q, a compound that has been reported to be a potent reversible CYP2D inhibitor in the rat (Kobayashi et al., 1989; Tomkins et al., 1997). In a pilot study carried out in rats receiving $Q$ in a short i.v. infusion (data not shown), Q did not elicit significant $(P>0.05)$ antinociception in the tail-flick test, and showed a short elimination half-life; thus considering the reversible nature of the interaction, in experiments I and II Q was infused for 40 or $80 \mathrm{~min}$ to ensure CYP2D inhibition during and after (+)-T administration. $\mathrm{Q}$ administered at doses of $20 \mathrm{mg} / \mathrm{kg}$ was able to suppress CYP2D activity in the rat (Tomkins et al., 1997) and $2.4 \mu \mathrm{M}(867 \mathrm{ng} / \mathrm{ml})$ corresponds to its $\mathrm{IC}_{50}$ value for the inhibition of the debrisoquine 4-hydroxylase activity in rat liver microsomes (Kobayashi et al., 1989). In our study a bolus i.v. dose of $4 \mathrm{mg} / \mathrm{kg}$ followed by $40 \mathrm{mg} / \mathrm{kg}$ given in 40- or 80-min infusions showed, at the end of the infusions, mean Q plasma concentrations of 7150 or $5135 \mathrm{ng} / \mathrm{ml}$, which, on the basis of literature data, would elicit maximum CYP2D inhibition. There are potential drawbacks in the use of $\mathrm{Q}$ to study the effects of a drug such as $\mathrm{T}$, since it is known that this compound induces the release and inhibits the reuptake of monoamines in rat brain tissue (Clement et al., 1998) and a contribution of this mechanism to the $\mu$-opioid analgesia has been reported and modeled (Garrido et al., 2000). However, the estimates of the potency of $Q$ for its monoamine uptake and release effects are higher compared with the plasma $\mathrm{Q}$ concentration achieved in our study (Clement et al., 1998).

The plasma (+)-T concentration versus time profiles was not apparently modified in the presence of $\mathrm{Q}$, despite the Q-induced decrease in $\mathrm{CL}_{\mathrm{M} 10}$. This observation is compatible with the complex metabolism of $\mathrm{T}$ shown in humans where several metabolites have been identified (Lintz et al., 1981), and with the fact that the estimate of $\mathrm{CL}_{\mathrm{M} 10}(0.0019 \mathrm{l} / \mathrm{min})$ represents only $23 \%$ of the total $(+)-\mathrm{T}$ elimination clearance (0.008 1/min). However, plasma (+)-M1 concentration versus time profiles showed a marked alteration; this finding reinforces the need for a simultaneous determination of T and M1 in $\mathrm{pk}$ and $\mathrm{pk} / \mathrm{pd}$ studies with $\mathrm{T}$. Our results confirm that formation of (+)-M1 is controlled by CYP2D activity in the rat. To quantify the extent of the Q-induced inhibition, modeling the data was required. In a first step a model incorporating the effects of $\mathrm{Q}$ on $\mathrm{CL}_{\mathrm{M} 10}$ was fitted to the data (dashed lines in Fig. 4); the resulted misfit justified the search for a more elaborate model. The model selected includes $\mathrm{Q}$ inhibition in $\mathrm{CL}_{\mathrm{M} 10}$ and $\mathrm{CL}_{\mathrm{MEO}}$. With this approach predictions were adequate to describe the data (solid line in Fig. 4). Although the inhibition of $\mathrm{CL}_{\mathrm{M} 10}$ was supported by literature data, the effect of $\mathrm{CL}_{\mathrm{MEO}}$ was unexpected. Therefore, a second experiment was performed with the goal of exploring the possible effects of Q on (+)-M1 elimination. The findings were clear and the observations confirmed the modeling results from experiment I. The estimate obtained for $E_{\text {MAX }}$ indicates that Q cannot completely inhibit the CYP2D activity, a result that is in accordance with findings from in vitro data (Kobayashi et al., 1989). The estimates of $\mathrm{IC}_{50}$ obtained for $\mathrm{CL}_{\mathrm{M} 10}(97.2 \mathrm{ng} / \mathrm{ml})$ and $\mathrm{CL}_{\mathrm{MEo}}$ [47.8 (experiment I) and 83 (experiment II) ng/ml] are of the same order and low compared with the concentrations of $\mathrm{Q}$ achieved in plasma (which indicates that little information about the lower portion of the inhibition versus concentration curves has been gained). Therefore, it is likely that $\mathrm{Q}$ could induce the inhibition of the formation and elimination of (+)-M1 with the same potency.

$\mathrm{Pk} / \mathrm{pd}$ modeling showed that the contribution of (+)-T to antinociception was negligible and antinociception is caused by the presence of (+)-M1, which is in agreement with the very low affinity of the parent drug for the $\mu$-opioid receptors (Raffa et al., 1992; Frink et al., 1996). This finding helps to complete the complex picture of the time course of $\mathrm{T}$ effects. Our pk/pd studies have demonstrated that (+)-M1, but not $(+)-\mathrm{T}$ and (-)-M1, can elicit maximum antinociception in the tail-flick test. In addition, (-)-M1 at high concentrations is able to contribute to the (+)-M1 antinociceptive effects. The modeling of the possible interaction between (-)-T and (+)-M1 is still missing and would require a more appropriate animal model for antinociception to explore the nonopioid component in the response (Le Bars et al., 2001). Due to the presence of censored observations, during the pk/pd modeling
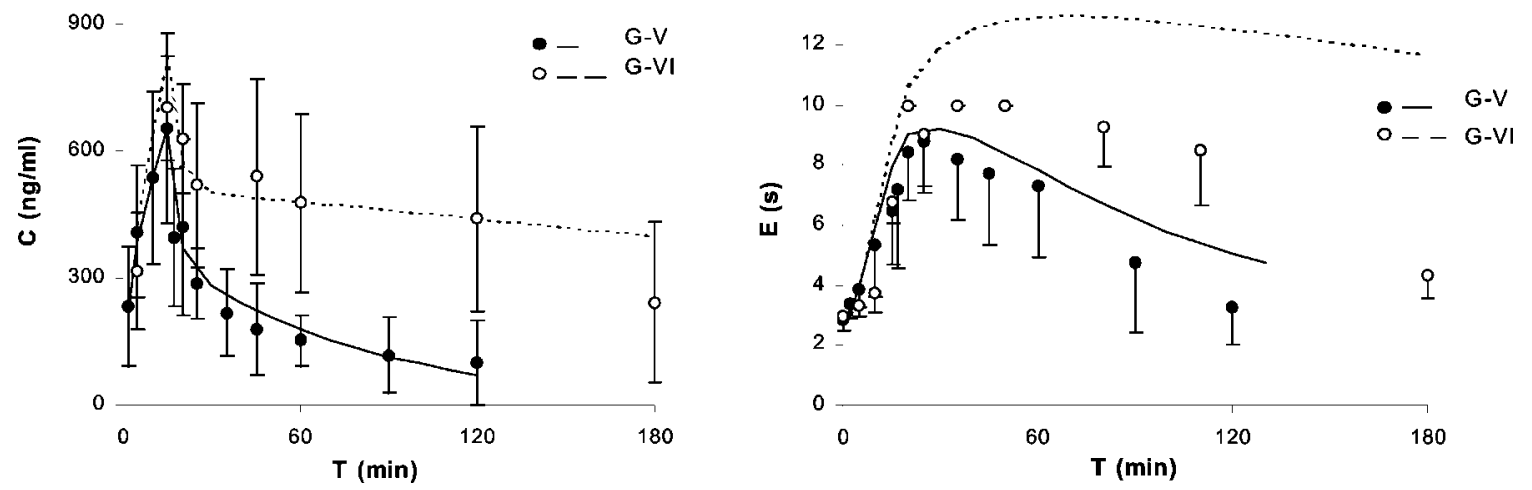

Fig. 6. Plasma (+)-M1 concentration (left panel) and effect (right panel) versus time profiles in groups V and VI. Symbols represent mean (G-V) or median (G-VI) raw data. Vertical lines in group V represent standard deviations; in the case of group VI, vertical lines show the dispersion in the data and have a value equal to the standard deviation of the mean. Lines show typical model predictions. 

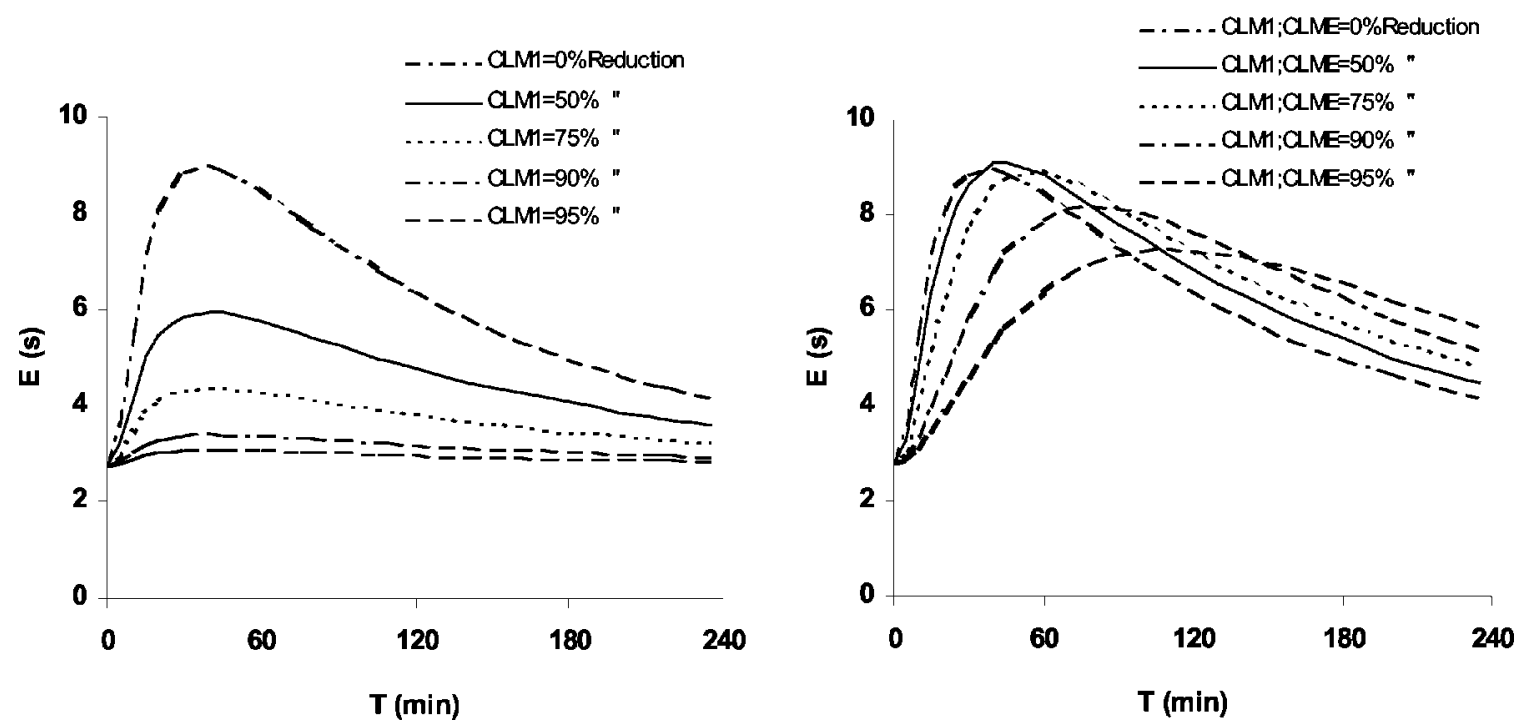

Fig. 7. Simulated effect versus time profiles in the presence of a constant $0,50,75,90$, and $95 \%$ reduction in $\mathrm{CL}_{\mathrm{M} 10}$ (left panel) and in both $\mathrm{CL}_{\mathrm{M} 10}$ and $\mathrm{CL}_{\mathrm{ME0}}($ right panel).

the time-to-event approach was used, which allows the correct use of the censored data. Nevertheless, the resulting selected models and estimates of model parameters are similar to those reported previously (Garrido et al., 2000; Valle et al., 2000).

Since (+)-M1 disposition depends only on CYP2D activity and response is only mediated by (+)-M1 in the effect site, CYP2D activity plays a major role in response. To further explore the impact of a decrease in CYP2D activity on drug effects the following simulation exercise was performed: the response versus time profiles were generated in cases of complete (100\%), $50,25,10$, or $5 \%$ inhibition of the initial CYP2D activity, assuming 1) only (+)-M1 formation is affected; and 2) both formation and elimination of (+)-M1 are affected. Figure 7 shows the results from the simulations. It is clear that in the case of an inhibition in both formation and elimination of (+)-M1 the impact of the altered CYP2D activity is mitigated, principally affecting the onset time of antinociception, resembling the observations obtained in the present study.
As a last comment, it is recognized that it would have been more elegant to fit all data from experiments I and II simultaneously. In fact, this was tried but (+)-M1 plasma versus time profiles from groups II and V were not described adequately, even though several models were explored. This result could be interpreted as an interaction between the parent drug and the metabolite at the pk level. However, the data from this study did not support the interaction models. Therefore, further experiments addressed to explore this issue should be designed.

In conclusion, CYP2D activity plays a crucial role in the antinociception after $(+)-\mathrm{T}$ administration since it controls the formation and elimination of the metabolite (+)-M1, which is the active compound. Results were obtained by modifying CYPD2D activity in the rat by administering its reversible inhibitor $\mathrm{Q}$. One of the main findings of the study is that CYP2D appears also to be involved in (+)-M1 elimination.

\section{APPENDIX I}

Results from the key models explored during the development of the pharmacokinetic model in the experiment I

Results listed show that the presence of $Q$ has a significant effect on both $\mathrm{CL}_{\mathrm{M} 1}$ and $\mathrm{CL}_{\mathrm{ME}}$ (models 2,3 , and $4 ; P<0.001$ ). The inclusion of another elimination route for the case of $(+)$-T was highly significant (model 5; $P<0.001$ ), and model 6 shows that such additional route was not significantly affected by $Q(P>0.05)$. Model 7 , which corresponds to the selected model, indicates that the estimation of different $\mathrm{IC}_{50}$ for the effect of $Q$ on $\mathrm{CL}_{\mathrm{M} 1}$ and $\mathrm{CL}_{\mathrm{ME}}$ improved the fit significantly $(P<0.01)$.

\begin{tabular}{|c|c|c|c|}
\hline Model & Model Structure & OBJ & $\triangle \mathrm{OBJ}$ \\
\hline 1 & $\begin{array}{l}\text { (+)-T: Two compartments; } \mathrm{CL}_{\mathrm{M} 2} ; \mathrm{CL}_{\mathrm{M} 1} \\
\text { (+)-M1: One compartment; } \mathrm{CL}_{\mathrm{MF}}\end{array}$ & 3501 & \\
\hline 2 & $\begin{array}{l}\text { (+)-T: Two compartments; } \mathrm{CL}_{\mathrm{M} 2} ; \mathrm{CL}_{\mathrm{M} 1} \sim I(Q) \\
\text { (+)-M1: One compartment; } \mathrm{CL}_{\mathrm{ME}}\end{array}$ & 3066 & $-435.0^{a}$ \\
\hline 4 & $\begin{array}{l}\text { (+)-T: Two compartments; } \mathrm{CL}_{\mathrm{ME}} ; \mathrm{CL}_{\mathrm{M} 1} \sim I(Q) \\
\text { (+)-M1: One compartment; } \mathrm{CL}_{\mathrm{ME}} \sim I(Q)\end{array}$ & 2973 & $-93.0^{b}$ \\
\hline 6 & $\begin{array}{l}\text { (+)-T: Two compartments; } \mathrm{CL}_{\mathrm{M} 2} \sim I(Q) ; \mathrm{CL}_{\mathrm{M} 1} \sim I(Q) \\
\text { (+)-M1: One compartment; } \mathrm{CL}_{\mathrm{ME}} \sim I(Q)\end{array}$ & 2973 & $0.0^{c}$ \\
\hline 7 & $\begin{array}{l}\text { (+)-T: Two compartments; } \mathrm{CL}_{\mathrm{M} 2} ; \mathrm{CL}_{\mathrm{M} 1} \sim I\left(Q, \mathrm{IC}_{50_{C} \mathrm{CLM} 1}\right) \\
\text { (+)-M1: One compartment; } \mathrm{CL}_{\mathrm{ME}} \sim I\left(Q, \mathrm{IC}_{50 \_ \text {CLME }}\right)\end{array}$ & 2964 & $-9.0^{c}$ \\
\hline
\end{tabular}

(+)-T, (+)-tramadol; (+)-M1, (+)-O-demethyltramadol; $\mathrm{CL}_{\mathrm{M} 1},(+)-\mathrm{M} 1$ formation plasma clearance; $\mathrm{CL}_{\mathrm{M} 2}$, clearance representing other routes of elimination; $\mathrm{CL}_{\mathrm{MF}}$ (+)-M1 plasma clearance; $Q$, predicted quinine plasma concentrations; $I 0$, inhibitory $E_{\mathrm{MAX}}$ model; $\mathrm{IC}_{50}$, level of $Q$ eliciting half of maximum $\mathrm{CL}_{\mathrm{M} 1}$ or $\mathrm{CL}_{\mathrm{ME}}$ inhibition; $\mathrm{OBJ}$, minimum value of the objective function; $\triangle \mathrm{OBJ}$, difference in OBJ.

$a, b, c \Delta \mathrm{OBJ}$ with respect to model 1 , model 2 , and model 4 , respectively. 


\section{APPENDIX II}

Results from the key models explored during the development of the pharmacokinetic/pharmacodynamic model in the experiment I

Results listed show that $C_{\mathrm{e}_{-}(+)-\mathrm{M} 1}$ (model 4$)$ is a significant $(P<0.001)$ better predictor of the antinociceptive effects than plasma concentrations of (+)-T, $C_{(+)-\mathrm{T}}$, (model 1), (+)-M1, $C_{(+)-\mathrm{M} 1}$ (model 2$)$, or $C_{\text {e(+)-T }}$ (model 3$)$. In model 5, an interaction between (+)-T and (+)-M1 was explored but the fit was not improved significantly $(P>0.05)$; the same results were found where the relationship between antinociception and $C_{\mathrm{e}(+)-\mathrm{M} 1}$ was modeled with an $E_{\mathrm{MAX}}$ model $(P>0.05)$

\begin{tabular}{clrr}
\hline Model & \multicolumn{1}{c}{ Structure } & OBJ & $\Delta$ OBJ \\
\hline 1 & Antinoception $=\operatorname{lin}\left(C_{(+)-\mathrm{T}}\right)$ & 1005 & \\
2 & Antinociception $=\operatorname{lin}\left(C_{-(+)-\mathrm{M} 1}\right)$ & 937 & $-68^{a}$ \\
3 & Antinoception $=\operatorname{lin}\left(C_{\mathrm{e}_{-}(+)-\mathrm{T}}\right)$ & 809 & $-128^{b}$ \\
4 & Antinociception $=\operatorname{lin}\left(\bar{C}_{\mathrm{e}_{-}(+)-\mathrm{M} 1}\right)$ & 714 & $-95^{c}$ \\
5 & Antinociception $=\operatorname{lin}\left(C_{\mathrm{e}_{-}(+)-\mathrm{M} 1}, C_{\mathrm{e}_{-}(+)-\mathrm{T}}\right)$ & 714 & $0^{d}$ \\
6 & Antinociception $=E_{\mathrm{MAX}}\left(C_{\mathrm{e}_{-}(+)-\mathrm{M} 1}\right)$ & 714 & $0^{d}$ \\
\hline
\end{tabular}

Lin 0, linear model; $C_{-(+)-\mathrm{T}}$, plasma (+)-T concentrations; $C_{-(+)-\mathrm{M} 1 \text {, plasma (+)-M1 }}$ concentrations; $C_{\mathrm{e}_{-}(+)-\mathrm{T}}$, effect site (+)-T concentrations; $C_{\mathrm{e}_{-}(+)-\mathrm{M} 1}$, effect site (+)-M1 concentrations; $E_{\mathrm{MAX}} 0, E_{\mathrm{MAX}}$ model; OBJ, minimum value of the objective function; $\triangle \mathrm{OBJ}$, difference in OBJ.

$a, b, c, d=\mathrm{OBJ}$ with respect to model 1 , model 2 , model 3 , and model 4 , respectively.

\section{References}

Abdel-Rahman SM, Marcucci K, Boge T, Gotschall RR, Kearns GL, and Leeder JS (1999) Potent inhibition of cytochrome P-450 2D6-mediated dextromethorphan $O$-demethylation by terbinafine. Drug Metab Dispos 27:770-775.

Al-Dabbagh SG, Idle JR, and Smith RL (1981) Animal modelling of human polymorphic drug oxidation - the metabolism of debrisoquine and phenacetin in rat inbred strains. J Pharm Pharmacol 33:161-164.

Beal SL and Sheiner LB (1992) NONMEM User's Guide. NONMEM Project Group, University of California, San Francisco.

Bertilsson L, Lou YQ, Du YL, Liu Y, Kuang TY, Liao XM, Wang KY, Reviriego J, Iselius L, and Sjöqvist F (1992) Pronounced differences between native Chinese and Swedish populations in the polymorphic hydroxylations of debrisoquine and S-mephenytoin. Clin Pharmacol Ther 51:388-397.

Brynne N, Forslund C, Hallén B, Gustafsson LL, and Bertilsson L (1999) Ketoconazole inhibits the metabolism of tolterodine in subjects with deficient CYP2D6 activity. Br J Clin Pharmacol 48:564-572.

Campanero MA, Calahorra B, Valle M, Troconiz IF, and Hororato J (1999) Enantiomeric separation of tramadol and its active metabolite in human plasma by chiral high-performance liquid chromatography: application to pharmacokinetic studies. Chirality 11:272-279.

Clement EM, Grahame-Smith DG, and Elliot JM (1998) Investigation of the presynaptic effects of quinine and quinidine on the release and uptake of monoamines in rat brain tissue. Neuropharmacology 37:945-951.

D'Amour FE and Smith DL (1941) A method for determining loss of pain sensation. J Pharmacol Exp Ther 72:74-769.

Frink MCH, Hennies HH, Englberger W, Haurand M, and Wilffert B (1996) Influence of tramadol on neurotransmitter systems of the rat brain. Arzneim-Forsch/ Drug Res 46:1029-1036.

Gårdmark M, Brynne L, Hammarlund-Udenaes M, and Karlsson MO (1999) Interchangeability and predictive performance of empirical tolerance models. Clin Pharmacokinet 36:145-167.

Garrido MJ, Valle M, Campanero MA, Calvo R, and Trocóniz IF (2000) Modeling of the in vivo antinociceptive interaction between an opioid agonist, (+)- $O$ demethyltramadol and a monoamine reuptake inhibitor, (-)-O-demethyltramadol, in rats. J Pharmacol Exp Ther 295:352-359.

Kahn GC, Rubenfield M, Davies DS, Murray S, and Boobis AR (1985) Sex and strain differences in hepatic debrisoquine 4-hydroxylase activity of the rat. Drug Metab Dispos 13:510-516.

Klein JP and Moeschberger ML (1997) Survival Analysis. Techniques for Censored and Truncated Data, Springer-Verlag, New York

Kobayashi S, Murray S, Watson D, Sesardic D, Davies DS, and Boobis AR (1989) The specificity of inhibition of debrisoquine 4-hydroxylase activity by quinidine and $\mathrm{Q}$ in the rat is the inverse of that in man. Biochem Pharmacol 38:2795-2799.

Lai J, Ma S, Porreca F, and Raffa RB (1996) Tramadol, M1 metabolite and enantiomer affinities for cloned human opioid receptors expressed in transfected HN9.10 neuroblastoma cells. Eur J Pharmacol 316:369-372.

Le Bars D, Gozariu M, and Cadden SW (2001) Animal models of nociception. Pharmacol Rev 53:597-652.

Lintz W, Erlacin S, Frankus E, and Uragg H (1981) Metabolismus von Tramadol be Mensch und Tier. Arzneim-Forsch/Drug Res 31:1932-1943.

Luks AM, Zwass MS, Brown RC, Lau M, Chari G, and Fisher DM (1998) Opioidinduced analgesia in neonatal dogs: pharmacodynamic differences between morphine and fentanyl. J Pharmacol Exp Ther 284:136-141.

Paar WD, Frankus P, and Dengler HJ (1992) The metabolism of tramadol by human liver microsomes. Clin Investig 70:708-710.

Paar WD, Poche S, Gerloff J, and Dengler HJ (1997) Polymorphic CYP2D6 mediates $O$-demethylation of the opioid analgesic tramadol. Eur J Clin Pharmacol 53:235239

Poulsen L, Arendt-Nielsen L, Brфsen K, and Sindrup SH (1996) The hypoalgesic effect of tramadol in relation to CYP2D6. Clin Pharmacol Ther 60:636-644.

Raffa RB and Friderichs E (1996) The basic science aspect of tramadol hydrochloride. Pain Rev 3:249-271.

Raffa RB, Friderichs E, Reimann W, Shank RP, Codd EE, and Vaught JL (1992) Opioid and nonopioid components independently contribute to the mechanism of action of tramadol, an "atypical" opioid analgesic. J Pharmacol Exp Ther 260:275285 .

Raffa RB, Nayak RK, Liao S, and Minn FL (1995) The mechanism(s) of action and pharmacokinetics of tramadol hydrochloride. Rev Contemp Pharmacother 6:485497.

Rhoda CL, McTavish D, and Sorkin EM (1993) Tramadol. A preliminary review of its pharmacodynamic and pharmacokinetic properties and therapeutic potential in acute and chronic pain states. Drugs 46:313-340.

Sheiner LB, Stanski DR, Vozeh S, Miller RD, and Ham J (1979) Simultaneous modeling of pharmacokinetics and pharmacodynamics: application to $d$ tubocurarine. Clin Pharmacol Ther 25:358-371.

Steimer JL, Mallet A, Golmard JL, and Boisvieux JF (1984) Alternative approache to estimation of population pharmacokinetic parameters: comparison with the nonlinear mixed-effect model. Drug Metab Rev 15:265-292.

Tomkins DM, Otton SV, Joharchi N, Li N-Y, Balster RF, Tyndale RF, and Sellers EM (1997) Effect of cytochrome P450 2D1 inhibition on hydrocodone metabolism and its behavioral consequences in rats. J Pharmacol Exp Ther 280:1374-1382.

Valle M, Garrido MJ, Pavón JM, Calvo R, and Trocóniz IF (2000) Pharmacokinetic pharmacodynamic modeling of the antinociceptive effects of main active metabolites of tramadol, (+)-O-demethyltramadol and (-)-O-demethyltramadol, in rats. $J$ Pharmacol Exp Ther 293:646-653.

Address correspondence to: Dr. Iñaki F. Trocóniz, Department of Pharmacy and Pharmaceutical Technology, School of Pharmacy, University of Navarra; Irunlarrea s/n, Pamplona 31080, Spain. E-mail: itroconiz@unav.es 